http://jmscr.igmpublication.org/home/ ISSN (e)-2347-176x ISSN (p) 2455-0450 crossref DOI: https://dx.doi.org/10.18535/jmscr/v8i1.04

\title{
Comparative Study of Induction Chemotherapy Followed by Concurrent Weekly Chemoradiotherapy vs 3-Weekly Chemoradiotherapy in Locally Advanced Head and Neck Cancer
}

\author{
Authors \\ Dr Pukhraj Sadh ${ }^{1}$, Dr Neeti Sharma ${ }^{2 *}$, Dr H.S.kumar ${ }^{3}$, Dr S.L. Jakhar ${ }^{4}$, \\ Dr Ranjeet Ram Jat ${ }^{5}$ \\ ${ }^{1}$ Resident Doctor, Radiation Oncology Department, ATRCTRI, S.P. Medical College, Bikaner \\ ${ }^{2}$ Professor and Head, Radiation Oncology Department, ATRCTRI, S.P. Medical College, Bikaner \\ ${ }^{3}$ Senior Professor, Radiation Oncology Department, ATRCTRI, S.P. Medical College, Bikaner \\ ${ }^{4}$ Associate Professor, Radiation Oncology Department, ATRCTRI, S.P. Medical College, Bikaner \\ ${ }^{5}$ Resident Doctor, Radiation Oncology Department, ATRCTRI, S.P. Medical College, Bikaner \\ *Corresponding Author
}

Dr Neeti Sharma

Professor and Head, Radiation Oncology Department, ATRCTRI, S.P. Medical College, Bikaner

\begin{abstract}
The purpose of the study was to assess difference in the treatment response and toxicity profile among two groups of unresectable locally advanced head and neck malignancies receiving concurrent weekly chemoradiotherapy vs 3-weekly chemoradiotherapy after completing neoadjuvant chemotherapy.

50 patients received neoadjuvant chemotherapy (inj. paclitaxel $175 \mathrm{mg} / \mathrm{m}^{2} \mathrm{Dl}$, Cisplatin $80 \mathrm{mg} / \mathrm{m}^{2}$ divided in 2 days \& inj $5 F U 1 \mathrm{gm} / \mathrm{m}^{2}$ iv d1 \& d2).Then randomly allotted into above two groups to receive 66 Gy fractionated RT along with concurrent weekly inj Cisplatin $40 \mathrm{mg} / \mathrm{m}^{2}$ in dayl versus RT along with concurrent 3 weekly inj Cisplatin $80 \mathrm{mg} / \mathrm{m} 2$ devided in day1 \& day2. Disease response was evaluated by RECIEST criteria.

All patients tolerated treatment well, no major adverse effects were monitored in two groups. There was no significant statistical difference in treatment response, which was found $84 \%$ vs $80 \%$ in concurrent weekly CTRT vs 3-weekly CTRT. however toxicity profile was higher in 3-weekly concurrent CTRT group. The 6 months PFS were $88 \%$ and $85.6 \%$ in CTRT and RT alone groups respectively; ( $p$ value $>0.05$ )

Keywords: Chemoradiotherapy, Induction chemotherapy, Unresectable locally advanced head and neck cancer.
\end{abstract}

\section{Introduction}

The incidence of squamous cell carcinoma of the head and neck (HNSCC) is increasing, with more than $70 \%$ of cases occurring in developing world $^{(1)}$. It is now the sixth most common malignancies, worldwide ${ }^{(2)}$ with an annual incidence of head and neck cancers worldwide is more than 550,000 cases with around 300,000 deaths each year ${ }^{(3)}$. Over 200,000 new cases of head and neck cancers are registered every year in India. In our institute Acharya Tulsi Regional Cancer Training And Research Institute 3671 new head and neck cases were registered in 2016. It is the second most common malignancy in India 
(most common in males while 4th most common in females). ${ }^{(4)}$ Male to female ratio ranges from $2: 1$ to $4: 1$. About $90 \%$ of all head and neck cancers are squamous cell carcinomas (HNSCC) probably due to their higher indulgence in risk factors such as alcohol and tobacco consumption. The median age at diagnosis is in the sixth decade of life. The prognosis of patients with locally advanced squamous cell cancer of head and neck (LASCCHN) is generally poor. In an attempt to improve local control of the tumor, investigators administered concomitantly with RT several drugs, such as cisplatin (DDP), 5-fluorouracil, mitomycin, and hydroxyurea, which are known to act as radio sensitizers ${ }^{(3,4)}$. The Concurrent chemoradiotherapy improves survival over radiotherapy alone, generally attributed to improved locoregional control. Induction chemotherapy reduces metastases incidence.

\section{Materials and Methods}

This was a randomised prospective study conducted at Acharya Tulsi Regional Cancer. Treatment And Research Institute, Sardar Patel Medical College and associated group of hospitals, Bikaner. The study protocol include 50 patients of histologically proven unresectable locally advanced squamous cell carcinoma of head and neck (LASCCN) of stage III-IV. Who were enrolled from April 2018 to Nov 2018. Inclusion criteria included inoperable, locally advanced, histologically proved stage III\&IV squamous cell carcinoma of head and neck patients, ECOG performance status 0-2. Age 1870 years, without any haematological, cardiac, renal or liver function abnormality, no previous history of treatment for the head and neck cancer and no any other concurrent malignancies.

All 50 patients were received three cycle of induction chemotherapy, each consisting of inj. Paclitaxel $175 \mathrm{mg} / \mathrm{m}^{2}$ on day1, inj Cisplatin $80 \mathrm{mg} / \mathrm{m}^{2}$ devided in two days and inj 5FU $1 \mathrm{gm} / \mathrm{m}^{2}$ on day1 \&2. Inj G-CSF administration after 48 hours of TPF chemotherapy cycle was implemented in the study. Prophylactic
Ciprofloxacin (500mg PO bid) was given to every patient from days 6-12 after TPF chemotherapy cycle. After 3-4 weeks from last cycle of chemotherapy patients were randomly assigned to two arms either weekly CTRT (arm A) or 3weekly CTRT (arm B), 25 patients in each. Patients in both arm received a total 66Gy in 33fr (2Gy per fraction), administered daily (5 days per week) for 5 weeks (conventional fractionated radiotherapy). Patients in study arm received radiotherapy along with weekly inj Cisplatin $40 \mathrm{mg} / \mathrm{m}^{2}$ day 1 . Patients in control arm received radiotherapy along with 3-weekly inj Cisplatin $80 \mathrm{mg} / \mathrm{m}^{2}$ divided in day $1 \&$ day 2 . Treatment volume were included primary tumor site plus neck node regions. Parallel opposed right-left lateral fields were planned. The dose was prescribed at midline. External beam radiotherapy was given with radiation therapy parameter on cobalt-60 machines Theratron 780E/ $780 \mathrm{C} /$ Bhabhatron II with photon energies of $1.25 \mathrm{MeV}$. Minimum treatment distance was $>=80$ cm SSD.

Patients were under monitoring after every course of chemotherapy and prior to \& during radiotherapy. In each monitoring, patients were assessed for treatment response, control of symptoms and any treatment related morbidity by doing complete blood counts, biochemistry profile consisting of RFT \& LFT, ENT examination, chest X-ray, USG Abdomen. Toxicity haematological, renal, biochemical, skin reactions and disease response were assessed. After 4-6 weeks of completion of chemoradiotherapy patients were called for first follow up visit and were assessed for treatment response and symptoms relief. On first follow up visit complete general-physical examination, ENT examination, haemogram, RFT, RBS \& CECT head and neck were done for treatment response \& toxicity evaluation and metastatic workup were consist of chest X-ray, USG Abdomen and LFT.

The primary object of study was to compare the efficacy of weekly concurrent chemoradiotherapy over 3-weekly concurrent chemoradiotherapy. 
Result of both arms were analysed \& compared in terms of various aspects like tumor response, symptom relief and treatment related toxicities.

\section{Results}

The baseline patients and tumor characteristics are shown in Table 1. No stastiscally significant difference was found in patients and tumor characteristics in both arms. The treatment Response at different follow-up visits are shown in Table 2, 3 and 4. The treatment related toxicities toxicities are shown in Table 5.

Table no 1: Patients Characteristics

\begin{tabular}{|c|c|c|}
\hline Patients characteristics & Study Arm & Control Arm \\
\hline \multicolumn{3}{|l|}{ Age (in years) } \\
\hline Median age & $55 \mathrm{yr}$ & $56 \mathrm{yr}$ \\
\hline Range & $38-70$ yrs & $36-69 \mathrm{yrs}$ \\
\hline \multicolumn{3}{|l|}{ Sex } \\
\hline Male & 22 & 23 \\
\hline Female & 3 & 2 \\
\hline \multicolumn{3}{|l|}{ ECOG } \\
\hline 0 & 10 & 9 \\
\hline 1 & 13 & 13 \\
\hline 2 & 2 & 3 \\
\hline \multicolumn{3}{|l|}{ Tumor stage } \\
\hline $\mathrm{T} 2$ & 3 & 2 \\
\hline T3 & 18 & 18 \\
\hline T4 & 4 & 5 \\
\hline \multicolumn{3}{|l|}{ Nodal stage } \\
\hline N0 & 7 & 12 \\
\hline N1 & 8 & 6 \\
\hline $\mathrm{N} 2$ & 9 & 5 \\
\hline N3 & 1 & 2 \\
\hline \multicolumn{3}{|l|}{ Group stage } \\
\hline Stage III & 13 & 15 \\
\hline Stage IV & 12 & 10 \\
\hline \multicolumn{3}{|l|}{ Anatomical site } \\
\hline Oral cavity/ Oropharynx & 16 & 17 \\
\hline Hypopharynx & 7 & 5 \\
\hline Larynx & 2 & 3 \\
\hline
\end{tabular}

Table no 2: Treatment response at 1 month after end of treatment

\begin{tabular}{|c|c|c|}
\hline Treatment response @ 4-6 weeks & \multicolumn{2}{|c|}{ Number of patients } \\
\cline { 2 - 3 } & $\begin{array}{c}\text { Study arm (25) } \\
100 \%\end{array}$ & $\begin{array}{c}\text { Control arm (25) } \\
100 \%\end{array}$ \\
\hline Regressive disease CR & $18(72 \%)$ & $16(64 \%)$ \\
PR & $03(12 \%)$ & $04(16 \%)$ \\
Total (CR+PR) & $21(84 \%)$ & $20(80 \%)$ \\
\hline Stable disease & $02(08 \%)$ & $02(08 \%)$ \\
\hline Progressive disease & $02(08 \%)$ & $03(12 \%)$ \\
\hline
\end{tabular}




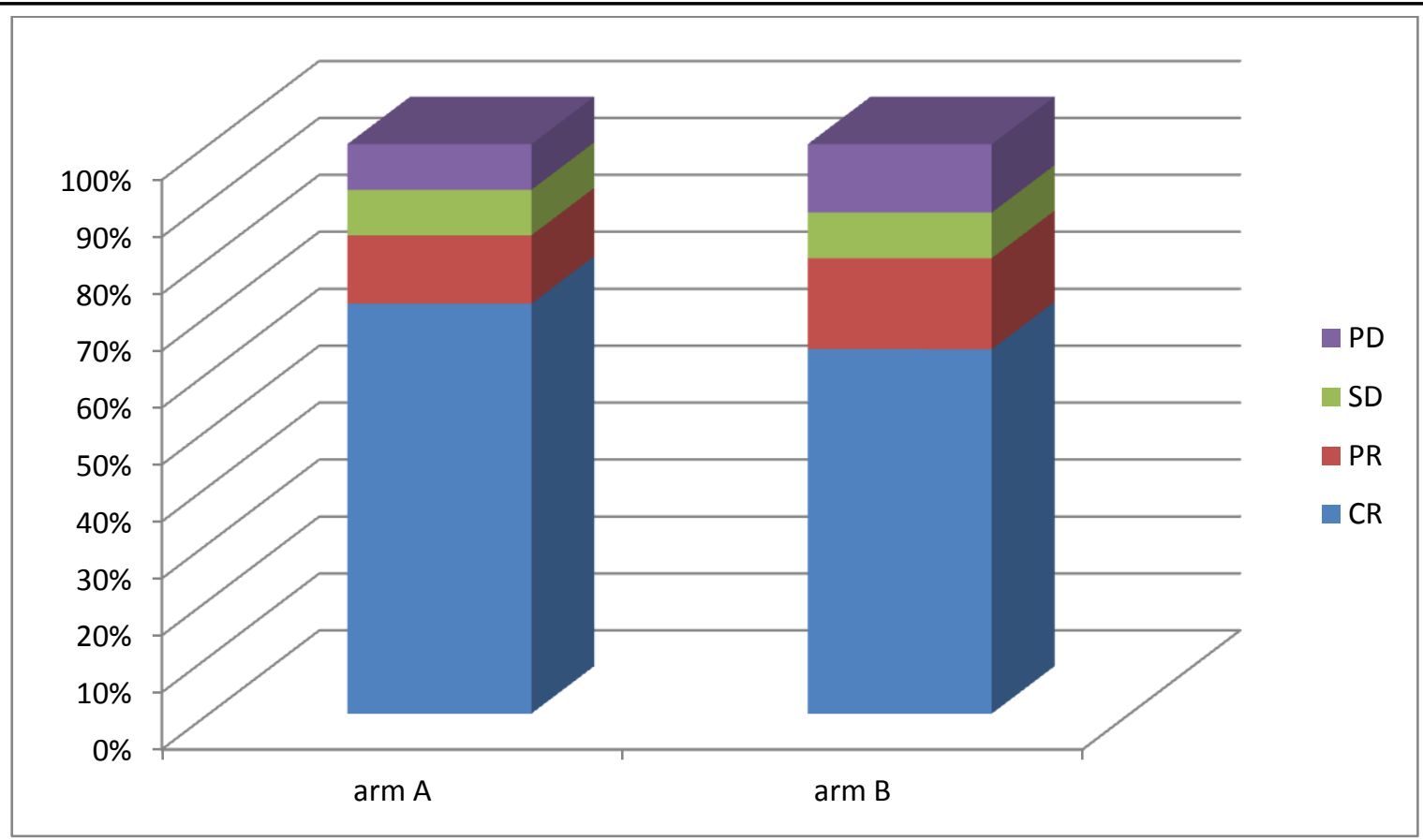

Figure 2: Treatment Response at 1 month after end of treatment

Table no 3: Treatment Response at 3 months after end of treatment

\begin{tabular}{|cc|c|c|}
\hline Treatment response @ 3 months & \multicolumn{2}{|c|}{ Number of patients } \\
\cline { 3 - 4 } & & Study arm (25) & Control arm (24) \\
\hline Regressive disease & CR & $100 \%$ & $100 \%$ \\
& PR & $07(60 \%)$ & $13(54.16 \%)$ \\
Total & (CR+PR) & $22(88 \%)$ & $07(29 \%)$ \\
\hline Stable disease & & $01(04 \%)$ & $20(83.3 \%)$ \\
\hline Progressive disease & & $02(08 \%)$ & $01(04.2 \%)$ \\
\hline
\end{tabular}

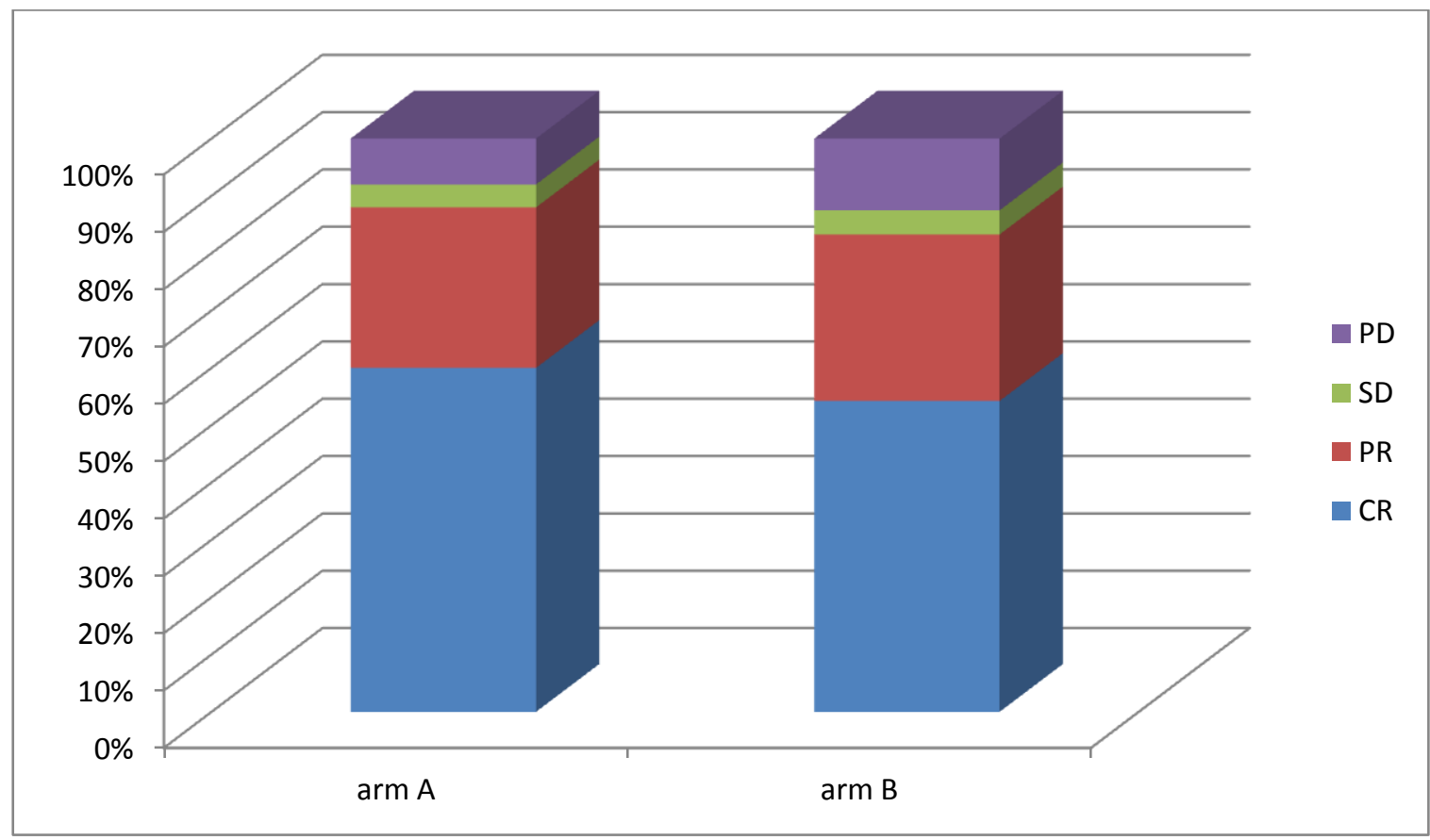

Figure 3: Treatment Response at 3 months after end of treatment 
Table no 4: Treatment Response at 6 months after end of treatment

\begin{tabular}{|cc|c|c|}
\hline \multirow{2}{*}{ Treatment response @ 6 months } & \multicolumn{2}{|c|}{ Number of patients } \\
\cline { 3 - 4 } & & Study arm (25) & Control arm (21) \\
& & $100 \%$ & $100 \%$ \\
\hline Regressive disease & CR & $10(40 \%)$ & $08(38.1 \%)$ \\
& PR & $11(44 \%)$ & $09(42.8 \%)$ \\
Total & (CR+PR) & $21(84 \%)$ & $17(80.9 \%)$ \\
\hline Stable disease & $01(04 \%)$ & $01(04.7 \%)$ \\
\hline Progressive disease & & $03(12 \%)$ & $03(14.3 \%)$ \\
\hline
\end{tabular}

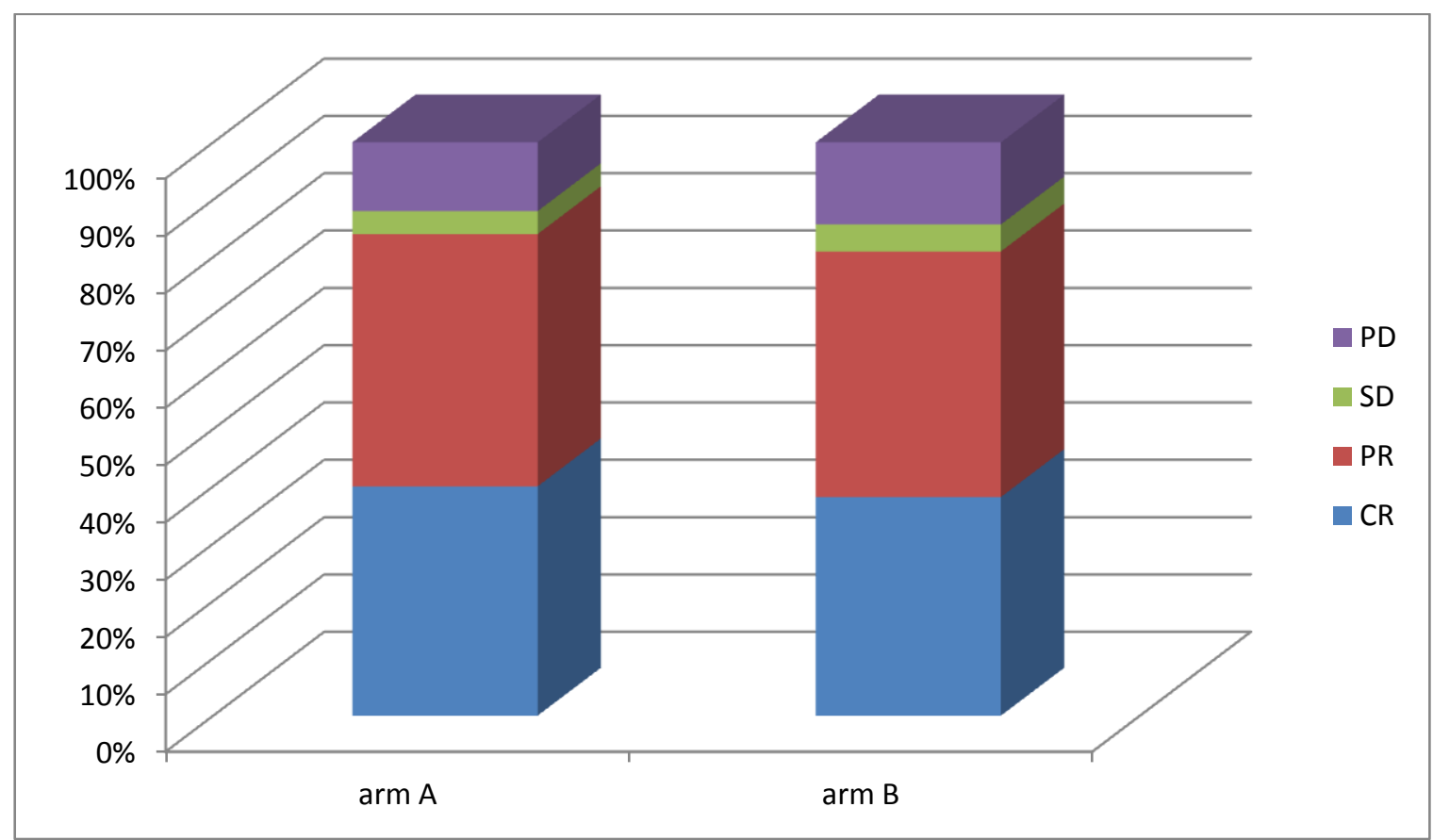

Figure 4: Treatment Response at 6 months after end of treatment

Table no 5 Acute Toxicities

\begin{tabular}{|l|}
\hline Toxicity \\
\begin{tabular}{|l|}
\hline Hematological \\
\hline anemia \\
\hline neutropenia \\
\hline thrombocytopenia \\
\hline \\
Non hematological \\
\hline Nausea \& vomiting \\
\hline Stomatitis \\
\hline Infection \\
\hline Decrease appetite \\
\hline Dysphagia \\
\hline Skin reaction \\
\hline Nephrotoxicity \\
\hline
\end{tabular}
\end{tabular}

Study arm
\begin{tabular}{|c|c|c|}
\hline Grade2 & Grade3 & Grade4 \\
\hline 6 & 0 & 0 \\
\hline 2 & 1 & 0 \\
\hline 1 & 0 & 0 \\
\hline
\end{tabular}

Control arm
\begin{tabular}{|c|c|c|}
\hline Grade2 & Grade 3 & Grade 4 \\
\hline 7 & 1 & 0 \\
\hline 3 & 2 & 0 \\
\hline 1 & 1 & 0 \\
\hline
\end{tabular}

\begin{tabular}{|c|c|c|}
\hline Grade2 & Grade3 & Grade4 \\
\hline 4 & 1 & 0 \\
\hline 15 & 6 & 0 \\
\hline 1 & 0 & 0 \\
\hline 5 & 1 & 0 \\
\hline 14 & 3 & 0 \\
\hline 16 & 4 & 0 \\
\hline 2 & 0 & 0 \\
\hline
\end{tabular}

\begin{tabular}{|c|c|c|}
\hline Grade2 & Grade3 & Grade4 \\
\hline 6 & 3 & 0 \\
\hline 17 & 8 & 0 \\
\hline 2 & 0 & 0 \\
\hline 6 & 2 & 0 \\
\hline 16 & 4 & 0 \\
\hline 17 & 6 & 0 \\
\hline 3 & 1 & 0 \\
\hline
\end{tabular}

Most of patients had ECOG performance status $0,1 \& 2$, median age $55 \mathrm{yr}$, male gender, median weight $51 \mathrm{~kg} \&$ stage III \& IV of locally advanced head and neck cancer in both arms. During the treatment none of the patient lost from follow up or three were expired in 3-weekly CTRT arms. Total 25 patients were received complete treatment in each arm. Eleven patients showed $>5 \%$ of weight loss during study; $4(16 \%)$ and $6(24 \%)$ patients from arm $\mathrm{A}$ and arm B respectively.

The follow up was done at 1 month after completion of chemo -radiotherapy, 18 and 16 patients had complete response in study \& control 
arm for any stage ( $\mathrm{p}>.05)$; which was insignificant. Although total $21 \& 20$ patients had regression ( $p>.05), 2 \& 2$ patients had stable disease and $2 \& 3$ patients had progression of disease in study \& control arm respectively. The 6 months PFS were $88.0 \%$ and $75.6 \%$ in CTRT and EBRT alone arm respectively ( $\mathrm{p}$ value>.05). Acute toxicities were the most common complications seen in the control population.. During the induction TPF hematological toxicities in terms of Anemia \& Neutropenia were managable. Most of the patients in both arms developed grade I,II anaemia and neutropenia. Grade III anaemia was seen in one patient in arm B. Grade III neutropenia was present in 1 case (4\%) of arm A and 2 cases $(8 \%)$ of arm B at treatment complication. Most patients had only grade II nausea and vomiting during the treatment. In arm $\mathrm{A}$ one patient (4\%) while in arm B, 3 patients(12\%) developed grade III nausea \& vomiting. Grade II skin reactions were seen in 16 cases (64\%) of arm A and 17 cases (68\%)of arm $\mathrm{B}$ ( $\mathrm{p}$ value $=>0.05)$. Grade III skin reaction were found 16\% (4 patients) in arm A and 24\%(6 patients) in arm B. Though skin reactions were disappeared at 3 months follow-up. In both arms patients had most commonly grade II stomatitis (15 patients in arm A and 17 patients in arm B ; p value $=>.05)$. Grade III stomatitis was present in 6 patients (24\%) of arm A and 8 patients (32\%) of arm $B ;(p$ value $=>0.05)$ at treatment completion. All patients recovered at 3 month follow-up. There were no any grade IV haematological \& nonhematological toxities were found in both arms. No grade IV toxicity seen in any of the arm. All toxicities were manageable and good treatment adherence was seen with all patients completing their treatment with no loss of follow up.

\section{Discussion}

Treatment of head and neck cancer is a multimodality approach, requiring surgery, chemotherapy and radiotherapy on the basis of the site and stage of the tumor.
A study by Lee et al published in medicine of Oncology 2018 alternative schedule with weekly low-dose cisplatin concurrent with radiation is as effective as 3 weekly standard-dose cisplatin in a large cohort of LA-HNSCC patients. In particular, weekly low-dose cisplatin might be tolerable with improved safety profiles even in medically unfit patients.

Our study was started with an intention to assess role of concurrent chemotherapy in locally advanced head and neck cancer. We observed that concurrent CTRT improve locoregional response but results are statistically not significant. Overall disease response was similar in both arms. So any of the regime can be used in patients depending on patients general condition.

Different studies have shown that infection with certain strains of human papilloma virus (HPV) is linked to the development of HNSCC.HPV infection accounts for the increasing incidence of HNSCC in younger population. The prognosis of HPV positive patients is substantially better than those associated with tobacco. The prevalence of human papilloma virus (HPV) in oropharyngeal cancers is roughly $25 \%$. HPV status, was unknown in our study and could be a confounding factor.

Three patients in 3-weekly CTRT arm \& no patients in weekly CTRT arm expired during 6 month follow up, but the deaths caused by disease itself were only one in control arm.

The expected higher proportion of febrile neutropenia during induction chemotherapy was controlled with prophylactic G-CSF, and Ciprofloxacin.

\section{Conclusion}

This study failed to show advantage of concurrent weekly chemoradiotherapy over 3-weekly chemoradiotherapy in terms of overall response rates and 6 months PFS in unresectable LASCCHN. The symptom relief was similar in both arms. The choice finally depends on patient's general condition. Small number of patients and 
relatively short follow-up remains the major limitations of this study.

\section{References}

1. Rodriguez CP, Adelstein DJ. Survival trends in head and neck Cancer: opportunities for improving outcomes. Oncologist. 2010;15:921-3.

2. Jakobsen KK, Grønhøj C, Jensen DH, Karnov KKS, Agander TK, Specht L, et al. Increasing incidence and survival of head and neck cancers in Denmark: a nationwide study from 1980 to 2014. Acta Oncol (Madr). 2018:1-9.

3. Megwalu UC, Sirjani D, Devine EE. Oropharyngeal squamous cell carcinoma incidence and mortality trends in the United States, 1973-2013. Laryngoscope. 2018;128:1582-8.

4. Brizel DM, Albers ME, Fisher SR, et al. Hyperfractionated irradiation with or without concurrent chemotherapy for locally advanced head and neck cancer. $\mathrm{N}$ Engl J Med 1998;338:1798-804.

5. Adelstein DJ, Li Y, Adams GL, et al. An intergroup phase III comparison of standard radiation therapy and two schedules of concurrent chemoradiotherapy in patients with unresectable squamous cell head and neck cancer. J Clin Oncol 2003;21:92-8.

6. Forastiere AA, Goepfert H, Maor M, et al. Concurrent chemotherapy and radiotherapy for organ preservation in advanced laryngeal cancer.N Engl J Med 2003;349:2091-8.

7. Adelstein DJ, Sharan VM, Earle AS, et al. Simultaneous versus sequential combined technique therapy for squamous cell head and neck cancer. Cancer. 1990;65(8):1685-1691.

8. Adelstein DJ, Li Y, Adams GL, et al. An intergroup phase III comparison of standard radiation therapy and two schedules of concurrent chemoradiotherapy in patients with unresectable squamous cell head and neck cancer. J Clin Oncol. 2003;21(1):92-98.

9. Forastiere AA, Zhang Q, Weber RS, et al. Long-term results of RTOG 91-11: a comparison of three nonsurgical treatment strategies to preserve the larynx in patients with locally advanced larynx cancer. J Clin Oncol. 2013;31(7):845-852.

10. Jemal A, Bray F, Center MM, Ferlay J, Ward E, Forman D. Global Cancer Statistics. CA Cancer J Clin 2011;61:6990.

11. Ries LAG, Melbert D, Krapcho M, Mariotto A, Miller BA, Feuer EJ, et al., Eds. SEER Cancer Statistics Review, 1975-2004. Bethesda, MD: National Cancer Institute; 2007. Available from: http://seer.cancer. gov/csr/1975_2004/. [Last accessed on $2017 \mathrm{Jul}$.

12. Ferlay J, Shin HR, Bray F, Forman D, Mathers C, Parkin DM. Estimation of worldwide burden of cancer in 2008. Globocan 2008 Int J Cancer 2010;127:2893-917.

13. Adelstein DJ, Li Y, Adams GL, Wagner H Jr, Kish JA, Ensley JF, Schuller DE, Forastiere AA. An intergroup phase III comparison of standard radiation therapy and two schedules of concurrent chemoradiotherapy in patients with unresectable squamous cell head and neck cancer. Journal of Clinical Oncology. 2003; 21:92-98.

14. NCCN Clinical Practice Guidelines in Oncology:Head and Neck Cancers, Version 1, 2015.

15. Pignon JP, le Maître A, Maillard E, Bourhis J, MACH-NC Collaborative Group. Meta-analysis of chemotherapy in head and neck cancer (MACH-NC): an update on 93 randomised trials and 17,346 patients. Radiotherapy and Oncology. 2009; 92:4-14. 
16. Adelstein DJ, Li Y, Adams GL, et al (2003). An intergroup phase III comparison of standard radiation therapy and two schedules of concurrent chemoraditherapy in patients with unresectable squamous cell head and neck cancer. J Clin Oncol, 21, 92-8.

17. Bachaud JM, Cohen-Jonathan E, Alzieu C, et al (1996). Combined postoperative radiotherapy and weekly cisplatin infusion for locally advanced head and neck carcinoma: final report of a randomized trial. Int J Radiat Oncol Biol Phys, 36, 999-1004.

18. Bernier J, Domenge C, Ozsahin M, et al (2004). Postoperative irradiation with or without concomitant chemotherapy for locally advanced head and neck cancer. $N$ Engl J Med, 350, 1945-52. 